\title{
PAN-EUROPEAN STUDY ON FUNCTIONAL AND MEDICAL RECOVERY AND GERIATRIC REHABILITATION SERVICES OF POST-COVID-19 PATIENTS: PROTOCOL OF THE EU-COGER STUDY
}

\author{
S. GRUND ${ }^{1, *}$, M.A.A. CALJOUW ${ }^{2, *}$, M.L. HAAKSMA ${ }^{2}$, A.L. GORDON ${ }^{3,4}$, R. VAN BALEN ${ }^{2}$, J.M. BAUER ${ }^{1}$, \\ J.M.G.A. SCHOLS ${ }^{5}$, W.P. ACHTERBERG ${ }^{2}$, COGER-STUDY SUBGROUP OF THE EUGMS-SIG ON GR ${ }^{6}$
}

\footnotetext{
1. Center for Geriatric Medicine, Agaplesion Bethanien Hospital Heidelberg, Geriatric Center at the Heidelberg University, Heidelberg, Germany; 2. Department of Public Health and Primary Care, Leiden University Medical Center, Leiden, the Netherlands; 3. Division of Medical Sciences and Graduate Entry Medicine, University of Nottingham, Derby Medical

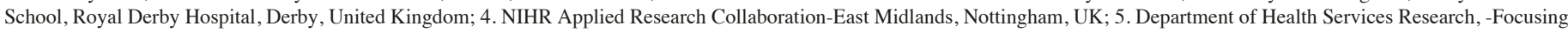
on Value-based Care and Ageing-and Department of Family Medicine, Caphri - Care and Public Health Research Institute, Maastricht University, Maastricht, The Netherlands; 6. COGER-Study Subgroup of the EuGMS SIG on GR: Clemens Becker, Department for Geriatric Medicine and Rehabilitation, Robert-Bosch-Krankenhaus, Stuttgart, Germany, Andreas S Stuck, Department of Geriatrics, University of Bern, Bern, Switzerland, Stefan Bachmann, Klinik für Rheumatologie und Rehabilitation des Bewegungsapparates, Rehabilitationszentrum Klinik Valens, Valens, Switzerland, Mirko Petrovic, Department of Internal medicine (Geriatrics), Faculty of Medicine and Health Sciences, Ghent University, Gent, Belgium, Nadezda Runikhina, Pirogov Russian National Medical University, The Russian Clinical Research Center for Gerontology, Moscow, Russia. Corresponding author: Stefan Grund, MD, MaHM, Center for Geriatric Medicine, Agaplesion Bethanien Hospital Heidelberg, Geriatric Center at the Heidelberg University, Rohrbacher Straße 149 , 69126 Heidelberg, Germany, Phone 004962213191730, FAX 004962213191513, Email: stefan.grund@bethanien-heidelberg.de
}

\begin{abstract}
Objectives: There is insufficient knowledge about the functional and medical recovery of older people infected with SARS-CoV-2. This study aims to gain insight into the course of functional and medical recovery of persons who receive geriatric rehabilitation (GR) following SARS-CoV-2 infection across Europe. Special attention will be paid to the recovery of activities of daily living (ADL) and to the GR services offered to these patients. Design: A multi-center observational cohort study. Setting and participants: This study will include several European countries (EuGMS member states) each providing at least 52 comparable routine datasets (core dataset) of persons recovering from a SARS-CoV-2 infection and receiving geriatric rehabilitation. The routine data will be anonymously collected in an online CASTOR database. The ethical regulations of each participating country will be followed. Primary outcome: ADL functioning. Secondary outcomes: length of stay, discharge destination, hospital readmission and mortality. Other variables that will be collected are quality of life, treatment modalities, complications, cognition, frailty, mood/anxiety, BMI, nutrition and pain. All variables will be reported at admission and compared with follow-up scores (discharge, 6 weeks and 6 months follow-up). Conclusion: This study will explore the effect of geriatric rehabilitation on post-COVID-19 patients, especially on ADL recovery, and the variety of geriatric rehabilitation services across Europe. Information from this study may help improve recovery of older persons infected with SARS-CoV-2 and improve geriatric rehabilitation services in the ongoing COVID-19 pandemic.
\end{abstract}

Key words: COVID-19, older persons, post-acute, geriatric rehabilitation, ADL functioning.

\section{Introduction}

The COVID-19 pandemic is hitting the world hard. Older people over the age of 70 years are more likely to get very ill when infected with SARS-CoV-2. The majority of patients admitted to the hospital with COVID-19 are in this age group. They have the highest morbidity and mortality all infected people. Some of them need intensive care, including ventilatory support. COVID-19 is often associated with prolonged hospitalisation and sequelae include multi-organ failure, pulmonary dysfunction, physical deconditioning, chronic fatigue, sarcopenia and pressure ulcers. There is also a high incidence of mental problems following COVID-19 including cognitive decline, Post-Traumatic Stress Disorder (PTSD) and Post-Intensive Care Syndrome (PICS) (1-4). To regain functional independence, many of these patients will need specialised rehabilitation.

Because COVID-19 is a new illness, with unique constellations of symptoms affecting multiple body systems (5), we do not know how the course of recovery for patients will be, or what treatment approaches will deliver the best outcomes. We do know from early experience in Italy, that the rehabilitation process is difficult, and the course is capricious $(6,7)$.

Geriatric rehabilitation is a multidimensional approach of diagnostic and therapeutic interventions, the purpose of which is to optimise functional capacity, promote activity and preserve functional reserve and social participation (8). Patients in geriatric rehabilitation have specific needs associated with the ageing process. For example, they have complex health issues including disabilities due to pre-existing conditions and geriatric syndromes such as frailty, cognitive impairment, and sensory loss. Geriatric rehabilitation is often delivered in parallel with acute geriatric care (9) which could be an advantage in post-COVID-19 patients, as periods of clinical instability, which require more intensive input by acute care teams, may be a feature.

It is known that infections are associated with deterioration in performance of activities of daily living (ADL) among vulnerable older people who had no ADL restrictions before 


\section{THE JOURNAL OF NUTRITION, HEALTH \& AGING}

the infection (10). So, it can be assumed that older people who have been infected with SARS-CoV-2 will also have limitations in ADL functioning and need special attention to support independence. One of the goals of geriatric rehabilitation is to enable older people to manage their ADL without the assistance of another person or to minimize the need for external assistance (11).

A number of COVID-19 patients have required intensive care admission, therefore rehabilitation experiences from other ICU patients may be useful as we learn how to rehabilitate those with COVID-19 (12-14). Rehabilitation principles applied in Post-Intensive Care Syndrome (PICS) may apply in addition to specialist pulmonary rehabilitation pathways currently used in older COPD patients (15). However, we are currently in the dark as to what the clinical characteristics of post-COVID-19 patients admitted for GR are, what treatment they receive, and what functional and clinical outcomes they have after geriatric rehabilitation. There is insufficient knowledge about the course of their disease and their functional and medical recovery.

The members of the Special Interest Group for Geriatric Rehabilitation of the European Geriatric Medical Society (EuGMS) designed this study to get insight into the course of functional and medical recovery in older persons affected by SARS-CoV-2 receiving geriatric rehabilitation across Europe.

Therefore this study aims to: 1) explore the course of ADL recovery and influencing factors; 2) describe other outcomes after geriatric rehabilitation in post-COVID-19 patients and; 3) describe geriatric rehabilitation services provided to postCOVID-19 patients across Europe.

\section{Methods}

\section{Design and study population}

An international multi-center observational cohort study. During one-year (October 2020 - October 2021), patients will be enrolled in the study in geriatric rehabilitation facilities of EuGMS members across Europe.

The study will be conducted according to the principles of the Declaration of Helsinki (2013 version) and in accordance with the General Data Protection Regulation (GDPR) and in full conformity to any applicable state or local regulations in the participating countries.

The study population will consist of older people rehabilitating after a SARS-CoV-2 infection in a geriatric rehabilitation setting in one of the participating European countries.

\section{Inclusion criteria}

- Recovering from a SARS-CoV-2 infection, confirmed with Polymerase Chain Reaction for viral RNA, serology for antibodies against SARS-CoV-2, or alternative tests as they become established and nationally mandated by individual governments.

- Accepted into a geriatric rehabilitation service, either institutionally-based or provided at home.

\section{Exclusion criteria}

- Presence of severe cognitive impairment, which leads to insufficient decisional capacities to participate in the study.

- Subjects who did not give informed consent, or who have opted out of using their anonymous data for research purposes where opt-out is an option.

\section{Recruitment and consent}

Eligible participants will be recruited in sites for geriatric rehabilitation in several countries, of which Germany, the Netherlands, Belgium, Switzerland, United Kingdom and Russia have already expressed intention to participate. In these sites, post-COVID-19 patients admitted for geriatric rehabilitation will be informed about the study and asked if they object to the use of their anonymized regular care data for research purposes to improve geriatric rehabilitation after COVID-19 infection. If they do, the data will not be used (optout procedure). In some countries this will be conducted under the guidelines for service evaluation and audit, as it uses routine data, held entirely by the clinical care team. Where this is not possible because of local legislation or guidelines, informed consent will be obtained. We propose to exclude participants who lack the mental capacity to consent to participation in research or service evaluation, as arrangements for inclusion of such participants are highly variable between countries. Such participants are unlikely to be common in geriatric rehabilitation facilities in most countries and we do not think, therefore, that our sample will be significantly biased by their exclusion.

\section{Geriatric Rehabilitation settings and treatment}

The settings in which geriatric rehabilitation is provided are heterogenous across EuGMS countries. In the Netherlands geriatric rehabilitation is mainly provided in, or run by, nursing homes, in the United Kingdom it can be provided in intermediate care facilities or community hospitals, and in Germany, Belgium, Switzerland and Russia it takes place in geriatric rehabilitation facilities or in special rehabilitation/ geriatric wards in the hospital. In several of these countries it can also be provided in the home environment with the support of specialist teams.

Participants will receive standard rehabilitation treatment according to the discretion of clinical teams, which will likely be adapted to the specific needs of post-COVID-19 patients. This treatment includes physical therapy, occupational therapy, and medical treatment by an advanced nursing practitioner, geriatrician or medical specialist. Additional ad hoc input by other therapists, including but not limited to speech and language therapists, dieticians, orthotists and podiatrists, will be captured. This study will not influence any therapy provided or decisions about the medical treatment or treatment programs already used in the participating geriatric rehabilitation setting. 
Table 1

Data collection scheme

\begin{tabular}{|c|c|c|c|}
\hline Variable & Admission & At discharge & Follow-up \\
\hline \multicolumn{4}{|l|}{ Participant characteristics } \\
\hline Year of birth/age & $\mathrm{X}$ & & \\
\hline Gender & $\mathrm{X}$ & & \\
\hline Residency premorbid & $\mathrm{X}$ & & \\
\hline \multicolumn{4}{|l|}{ Hospital/general practitioner } \\
\hline Hospital admission and number of days hospital admission & $\mathrm{X}$ & & \\
\hline Stay at ICU and days at ICU & $\mathrm{X}$ & & \\
\hline Complications during hospital stay & $\mathrm{X}$ & & \\
\hline Complications at home & $\mathrm{X}$ & & \\
\hline COVID-19 diagnosis confirmed (PCR/Serology) & $\mathrm{X}$ & & \\
\hline \multicolumn{4}{|l|}{ Geriatric rehabilitation } \\
\hline Pre-morbid ADL functioning (2 weeks prior to hospital admission) & $\mathrm{X}$ & & \\
\hline ADL functioning & $\mathrm{X}$ & $\mathrm{X}$ & $\mathrm{X}$ \\
\hline Frailty pre-admission ( 2 weeks prior to hospital admission) & $\mathrm{X}$ & & \\
\hline Frailty & $\mathrm{X}$ & & \\
\hline Body Mass Index before COVID-19 infection & $\mathrm{X}$ & & \\
\hline Body Mass Index & $\mathrm{X}$ & $\mathrm{X}$ & \\
\hline Nutrition & $\mathrm{X}$ & $\mathrm{X}$ & \\
\hline Comorbidity & $\mathrm{X}$ & & \\
\hline Fatigue & $\mathrm{X}$ & $\mathrm{X}$ & \\
\hline Dyspnoea & $\mathrm{X}$ & $\mathrm{X}$ & \\
\hline Pain & $\mathrm{X}$ & $X$ & \\
\hline Quality of life & $\mathrm{X}$ & $X$ & $\mathrm{X}$ \\
\hline Complications during GR stay & & $\mathrm{X}$ & \\
\hline Length of stay & & $\mathrm{X}$ & \\
\hline Discharge destination & & $\mathrm{X}$ & \\
\hline Cognition & $\mathrm{X}$ & $\mathrm{X}$ & \\
\hline Mood/anxiety/depression & $\mathrm{X}$ & $\mathrm{X}$ & \\
\hline \multicolumn{4}{|l|}{ By indication/optional: } \\
\hline Swallowing problems & $\mathrm{X}$ & & \\
\hline Speech problems & $\mathrm{X}$ & & \\
\hline Timed up and Go test & $\mathrm{X}$ & $X$ & \\
\hline MRC biceps/quadriceps & $\mathrm{X}$ & $\mathrm{X}$ & \\
\hline Hand grip strength & $X$ & $\mathrm{X}$ & \\
\hline Post-traumatic stress syndrome & & & $\mathrm{X}$ \\
\hline
\end{tabular}


Table 2

Assessments used for routine care in the countries

\begin{tabular}{|c|c|c|c|c|c|c|c|}
\hline Domain & Variable & NL & DE & UK & $\mathbf{R U}$ & $\mathbf{C H}$ & $\mathbf{B E}$ \\
\hline ADL & ADL functioning & USER; Barthel Index & Barthel Index & Barthel Index & Barthel Index & FIM & Barthel Index \\
\hline Quality of life & EQ-5D-5L & EQ-5D-5L & EQ-5D-5L & EQ-5D-5L & EQ-5D-5L & EQ-5D-5L & EQ-5D-5L \\
\hline Frailty & Frailty & Clinical Frailty Scale & $\begin{array}{l}\text { Clinical Frailty } \\
\text { Scale (translated } \\
\text { German Version) }\end{array}$ & $\begin{array}{l}\text { Clinical Frailty } \\
\text { Scale }\end{array}$ & $\begin{array}{l}\text { Clinical Frailty } \\
\text { Scale }\end{array}$ & $\begin{array}{l}\text { Clinical Frailty } \\
\text { Scale }\end{array}$ & $\begin{array}{l}\text { Clinical Frailty } \\
\text { Scale }\end{array}$ \\
\hline \multirow[t]{2}{*}{ Nutrition } & $\begin{array}{l}\text { Body Mass Index } \\
\text { (BMI) }\end{array}$ & BMI & BMI & BMI & BMI & BMI & BMI \\
\hline & Malnutrition & SNAQ65 & NRS/ MNA & MUST & MNA & NRS & MNA \\
\hline Comorbidity & Comorbidity & wFCI & wFCI & wFCI & wFCI & wFCI & CIRS-G/wFCI \\
\hline \multirow[t]{2}{*}{ Cognition } & $\begin{array}{l}\text { Cognitive impair- } \\
\text { ment }\end{array}$ & USER & MMSE/ Demtect & MOCA & MMSE/MOCA & MMSE/MOCA & MMSE/ MOCA \\
\hline & Delirium & DOS & $4 \mathrm{AT}$ & $4 \mathrm{AT}$ & $4 \mathrm{AT}$ & SQiD & DOS, 4AT \\
\hline Mood/anxiety & Depression & USER & GDS-15 & GDS-15 & GDS-15 & GDS-15 & GDS-15 \\
\hline Pain & $\begin{array}{l}\text { Numeric rating } \\
\text { scale (NRS-P) }\end{array}$ & NRS-P & NRS-P & NRS-P & NRS-P & NRS-P & NRS-P \\
\hline Skin & $\begin{array}{l}\text { Pressure ulcer: } \\
\text { yes/no }\end{array}$ & Yes & Yes & Yes & Yes & Yes & Yes \\
\hline \multirow[t]{2}{*}{ symptoms } & Fatigue: yes/no & Yes & Yes & Yes & Yes & Yes & Yes \\
\hline & Dyspnoea: yes/no & Yes & Yes & Yes & Yes & Yes & Yes \\
\hline \multicolumn{8}{|l|}{ Optional: } \\
\hline Mobility/balance & Performance & TUG & TUG & TUG & TUG & TUG & TUG \\
\hline Muscle strength & $\begin{array}{l}\text { MRC biceps/qua- } \\
\text { driceps }\end{array}$ & $\begin{array}{l}\text { MRC biceps/ qua- } \\
\text { driceps }\end{array}$ & $\begin{array}{l}\text { MRC biceps/ qua- } \\
\text { driceps }\end{array}$ & $\begin{array}{l}\text { MRC biceps/ } \\
\text { quadriceps }\end{array}$ & $\begin{array}{l}\text { MRC biceps/ } \\
\text { quadriceps }\end{array}$ & $\begin{array}{l}\text { MRC biceps/ } \\
\text { quadriceps }\end{array}$ & $\begin{array}{l}\text { MRC biceps/ } \\
\text { quadriceps }\end{array}$ \\
\hline Post-traumatic stress syndrome & PTSS & Yes & Yes & Yes & Yes & Yes & Yes \\
\hline \multirow[t]{2}{*}{ Speech/swallowing } & $\begin{array}{l}\text { Swallowing: } \\
\text { yes/no }\end{array}$ & Yes & Yes & Yes & Yes & Yes & Yes \\
\hline & Speech: yes/no & Yes & Yes & Yes & Yes & Yes & Yes \\
\hline
\end{tabular}

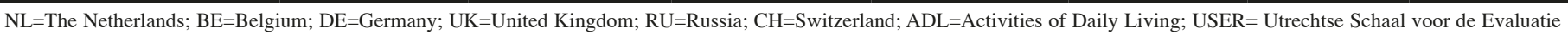

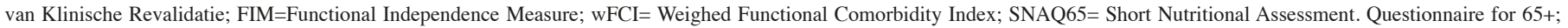

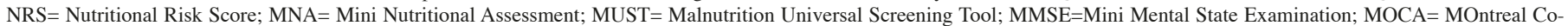

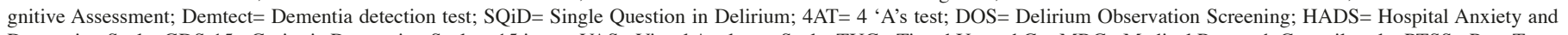

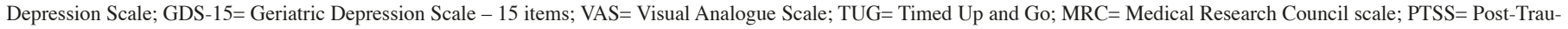
matic Stress Syndrome

\section{Outcome measures}

\section{Primary outcome}

The primary outcome measure is: ADL functioning.

ADL functioning will be assessed with the Barthel Index, Utrecht Scale for the Evaluation of Rehabilitation (USER) or Functional Independence Measure (FIM), depending on use in the participating country. The USER $(16)$ and FIM $(17,18)$ will be converted afterwards to the Barthel Index using standardised approaches.

\section{Secondary outcomes}

The secondary outcomes are separated into functional and medical outcome measures and rehabilitation descriptors (19).

\section{Functional and medical outcome measures}

Additional functional and medical outcomes include: complications, nutritional status (including Body Mass Index), performance of mobility/balance, muscle strength, fatigue, dyspnea, cognition, mood, pain, quality of life, post-traumatic stress syndrome and mortality

\section{Rehabilitation descriptors}

General rehabilitation descriptors are length of stay, discharge destination, and hospital readmission. GR service descriptors are kind of professionals involved, and kind of treatment given.

\section{Data collection}

For each participating geriatric rehabilitation facility in Europe one instructed local care professional will complete an online CASTOR database (20) in which anonymous data from the clinical records of the included patients will be collected at admission, discharge and 6 weeks and 6 months follow-up (see table 1: data collection scheme). These data concern: 
PROTOCOL OF THE EU-COGER STUDY”

Table 3

Assessment domains and instruments - Core data set and data homogenization

\begin{tabular}{|c|c|c|c|}
\hline Domain & Variable & Core data set & Data homogenization \\
\hline ADL & ADL functioning (Barthel Index, USER, FIM) & $\begin{array}{l}\text { USER; FIM } \\
\text { Barthel Index }\end{array}$ & $\begin{array}{l}\text { Conversion into } \\
\text { Barthel Index (0-20 pts.) }\end{array}$ \\
\hline Quality of life & EQ-5D-5L / EQ-5D VAS & EQ-5D-5L / EQ-5D VAS & $\begin{array}{l}\text { EQ-5D-5L (tariff/country), } \\
\text { EQ-5D VAS (0-100 pts.) }\end{array}$ \\
\hline Frailty & Frailty (Clinical Frailty Scale) & Clinical Frailty Scale & Clinical Frailty Scale (1-9 pts.) \\
\hline \multirow[t]{2}{*}{ Nutrition } & Body Mass Index (BMI) & $\mathrm{BMI}\left(\mathrm{kg} / \mathrm{m}^{2}\right)$ & $\operatorname{BMI}\left(\mathrm{kg} / \mathrm{m}^{2}\right)$ \\
\hline & Malnutrition (SNAQ65, MNA, MUST, NRS) & SNAQ65/ NRS/MNA/MUST & $\begin{array}{l}1=\text { suspicious }(\mathrm{MNA} \leq 11 \text { pts., } \mathrm{NRS} \geq 3 \\
\text { pts., } \mathrm{MUST} \geq 2 \text { pts., } \mathrm{SNAQ} 65=\text { moderate/ } \\
\text { high risk) } \\
0=\text { non suspicious }\end{array}$ \\
\hline Comorbidity & Comorbidity (Weighed Functional Comorbidity Index) & wFCI & wFCI (0-36 pts) \\
\hline \multirow[t]{2}{*}{ Cognition } & Cognitive impairment (MOCA, MMSE-2, Demtect) & USER/ MMSE/ MOCA/ Demtect & $\begin{array}{l}1=\text { suspicious, }(\mathrm{MMSE} \leq 27 \mathrm{pts}, \text { Demtect } \\
\leq 12 \text { pts., } \text { MOCA } \leq 26 \text { pts. }) \\
0=\text { non suspicious }\end{array}$ \\
\hline & Delirium (DOS, 4AT, SQiD) & DOS/ 4AT/ SQiD & $\begin{array}{l}1=\text { suspicious }(4 \mathrm{AT}>3 \text { pts., } \mathrm{DOS}>3 \text { pts., } \\
\mathrm{SQiD}>0 \text { ) } \\
0=\text { non suspicious }\end{array}$ \\
\hline Mood/anxiety & Depression (HADS, GDS) & HADS/ GDS-15 & $\begin{array}{l}1=\text { suspicious ( } \mathrm{GDS} \geq 6 \text { pts., } \mathrm{HADS} \geq 8 \\
\text { pts.) } \\
0=\text { non suspicious }\end{array}$ \\
\hline Pain & Numeric rating scale $(N R S-P)$ Pain & NRS-P & NRS-P (0-10 pts.) \\
\hline Skin & Pressure ulcer: yes/no & Pressure sores query & $\begin{array}{l}1=\text { yes }=\text { existing } \\
0=\text { no }=\text { non existing }\end{array}$ \\
\hline \multirow[t]{2}{*}{ Symptoms } & Fatigue & VAS-scale & VAS-scale (0-10 pts.) \\
\hline & Dyspnoea & VAS-scale & VAS-scale (0-10 pts.) \\
\hline Mobility/balance & Performance (Timed up and Go) & TUG & TUG (seconds) \\
\hline Muscle strength & MRC biceps/quadriceps & MRC biceps/quadriceps & MRC biceps (0-5pts.)/quadriceps (0-5pts.) \\
\hline Post-traumatic stress syndrome & PTSS & PTSS (Yes/No) & $\begin{array}{l}1=\text { yes }=\text { PTSS existing } \\
0=\text { no }=\text { PTSS not existing }\end{array}$ \\
\hline \multirow[t]{2}{*}{ Speech/swallowing } & Swallowing & Swallowing problems (Yes/No) & $\begin{array}{l}1=\text { yes }=\text { Swallowing problems existing } \\
0=\text { no }=\text { Swallowing problems not existing }\end{array}$ \\
\hline & Speech & Speech problems (Yes/No) & $\begin{array}{l}1=\text { yes }=\text { Speech problems existing } \\
0=\text { no }=\text { Speech problems not existing }\end{array}$ \\
\hline
\end{tabular}

pts.=points; ADL=Activities of Daily Living; USER=Utrechtse Schaal voor de Evaluatie van Klinische Revalidatie; FIM=Functional Independence Measure; SNAQ65= Short Nutri-

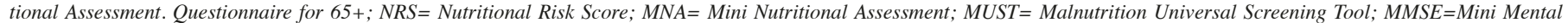

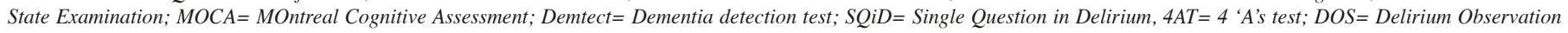

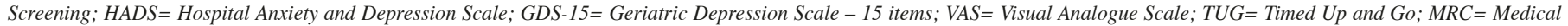
Research Council scale; PTSS= Post-Traumatic Stress Syndrome

a. Demographic data: Year of birth/age, gender, comorbidity, and premorbid residency of the participants.

b. Prior information from hospital or general practitioner (GP): number of days of hospital admission, number of days at the ICU, complications during hospital stay or at home (Thromboembolism, Delirium, Pressure Ulcer), and SARSCoV-2 diagnosis confirmed by PCR or Serology.

c. At admission and discharge in geriatric rehabilitation: in all participants, a core dataset, which includes the primary and secondary outcome parameters, will be collected. See table 1 for an overview of these outcome parameters. These data are already routinely collected in regular geriatric rehabilitation. At discharge we will additionally collect information from the treatment plan about which professionals have been involved during geriatric rehabilitation and which treatment interventions have been applied.

d. Follow-up: at 6 weeks, 6 months following regular care in the participating countries: ADL functioning, quality of life, and post-traumatic stress syndrome.

\section{Core data set and data homogenization}

As shown in Table 2, the assessments used for the routine care are very heterogeneous among the participating countries. In order to be able to obtain comparable data, the core data set of the study is homogenized (see Table 3 ).

\section{Sample size calculation}

The primary outcome is ADL functioning (Barthel index or derived from the USER or FIM). The Barthel index is recommended to be used as ADL measure for research and 


\section{THE JOURNAL OF NUTRITION, HEALTH \& AGING}

care practice in older populations (21). In our study, ADL functioning will be measured repeatedly in each participant. Therefore we performed a power calculation for a paired sample t-test on the primary outcome ADL functioning (Barthel index). We assume a minimal clinically important difference of 2 points on the Barthel index as relevant (22); this is the mean difference between Barthel score at admission and Barthel score at discharge $(23,24)$. Therefore the study would require a sample size of 52 (number of pairs) to achieve a power of $80 \%$ and a level of significance of 5\% (two sided), for detecting a mean of the differences of 2 between pairs, assuming the standard deviation of the differences to be 5 .

\section{Statistical analysis}

Descriptive statistics will be used to give an overview of characteristics of the participants in the participating countries for all primary and secondary outcomes.

A paired sample student t-test will be used to test the difference between ADL functioning at admission and followup per participating country.

Multivariable analyses will be used to evaluate the influence of individual factors (age, gender, comorbidities using modified Charlson comorbidity index (25) and frailty status before COVID-19 infection) as well as GR service factors (rehabilitation team structure, treatment intensity, treatment modalities) on changes in ADL functioning between admission and follow up.

For the other variables (paired) sample student t-tests and Mann-Whitney U-tests will be used for parametric and nonparametric continuous or ordinal variables respectively, whilst or chi-square tests will be categorical variables.

No imputation will be used for missing data. We will report the proportion of missing data for each variable. The level of significance will be set at $\mathrm{p}<0.05$.

\section{Discussion}

Post-acute care, including rehabilitation, is an important aspect of the recovery of COVID-19 survivors in many countries around the world (26). While most studies and statements of patient rehabilitation that are currently underway focus on adapted conventional rehabilitation in acute care (27) or post-acute care settings (28-31), the present study examines the outcome and structural adjustments of post-acute geriatric rehabilitation for post-COVID-19 patients.

In contrast to many other current COVID-studies $(27,32)$, the present study is a multi-center study. The Pan-European approach of this study will enable us to understand the spectrum of geriatric rehabilitation services for post-COVID-19 patients across Europe.

Because geriatric rehabilitation structures are heterogenous in Europe (33), the baseline and outcome measures used in routine practice are also heterogenous. To overcome this barrier a homogenization process of the core data set will be performed in order to remove inconsistencies in interpretation of the cut-off points of the assessments used. Post-acute geriatric rehabilitation services, which includes therapy modalities, and the team members involved will be evaluated and compared between participating countries.

This study will focus on a prospective observation of routine medical and therapeutic care adaptions in post-acute geriatric rehabilitation of the new patient group «post-COVID-19 survivors», excluding patients without COVID-19.

The study will identify specific requirements for and barriers to successful rehabilitation of older COVID-19 survivors. This will help in the future to better prepare and triage these persons for geriatric rehabilitation and to focus on special therapies during COVID-19 geriatric rehabilitation. We will also gain a sense of how geriatric rehabilitation services work across the continent in times of pandemic.

\section{Strengths and limitations}

This is the first study examining COVID-19 rehabilitation on a European level. It uses routine care data and therefore requires minimal time investment of care providers. This study will provide knowledge about the effect of routine post-acute geriatric rehabilitation care on recovery of ADL in older postCOVID-19 persons. In addition, it will provide insight into the variety of geriatric rehabilitation services offered in different European countries during the SARS-CoV-2 pandemic. Differences in routine post-acute geriatric rehabilitation care results and structures between different European countries will be assessed.

A limitation of this study is the observational study design and the likeliness of missing data due to the use of routine care data. Another limitation is that the study does not cover all post-acute geriatric rehabilitation patients. Patients with severe cognitive impairment, which leads to insufficient decisional capacities to participate in the study, will be excluded. Observational studies can measure correlation between exposures and outcomes but cannot imply causality because of the absence of control data. We will, however, be able to make important inferences because of the likely size of the sample and the expected variation in practice between European countries. Due to the use of routinely collected data, inferences from this study will be restricted to the variables collected in routine practice. The choice of the Barthel Index (ADL functioning) as the primary outcome will be affected by the usual limitations of this measure, including ceiling effects (the inability to measure improvements beyond the maximum threshold) and the fact that the Barthel Index is an ordinal, rather than a continuous scale. However, we expect that the Barthel Index is sensitive enough to capture the change in ADL among post-COVID-19 patients.

\section{Conclusion}

This study will explore the effect of geriatric rehabilitation on post-COVID-19 patients, especially on ADL recovery, and 


\section{PROTOCOL OF THE EU-COGER STUDY"}

the variety of geriatric rehabilitation services across Europe. Information from this study may help improve recovery of older persons infected with SARS-CoV-2 and improve geriatric rehabilitation services in the ongoing COVID-19 pandemic.

\section{Key summary points}

- This study evaluates the course of functional and medical recovery during routine geriatric rehabilitation care in older people affected by SARS-CoV-2.

- This multi-center observational cohort study will include facilities in several European countries and observe functioning in Activities of Daily Living, length of stay, discharge destination, hospital readmission and mortality as outcomes.

- Information from this study may help improve recovery of older people infected with SARS-CoV-2 and the geriatric rehabilitation services offered to them, and also inform development of services beyond the pandemic.

Ethical approval: This article does not contain any studies with human participants performed by any of the authors.

\section{Funding: This study is not funded.}

Conflicts of interest/Competing interests: All authors declare to have no conflicts of interests.

Authors' contributions: SG, MAAC, MLH, ALG, RvB, JMB, JMGAS, WPA contributed to the conception of the study, and writing the protocol. SG, MAAC and MLH contributed to drafting and critical revision of the manuscript. ALG conducted a final proof-read for written English. All authors have read and approved the final version of the manuscript.

Open Access: This article is distributed under the terms of the Creative Commons Attribution 4.0 International License (http://creativecommons.org/licenses/by/4.0/), which permits use, duplication, adaptation, distribution and reproduction in any medium or format, as long as you give appropriate credit to the original author(s) and the source, provide a link to the Creative Commons license and indicate if changes were made.

\section{References}

1. Sun P, Qie S, Liu Z, et al. (2020) Clinical characteristics of 50,466 hospitalized patients with 2019-nCoV infection. J Med Virol. doi:10.1002/jmv.25735

2. Wang YXJ, Liu WH, Yang M, Chen W (2020) The role of CT for Covid-19 patient's management remains poorly defined. Ann Transl Med. doi:10.21037/atm.2020.02.71

3. Liu Y, Yang Y, Zhang C, et al. (2020) Clinical and biochemical indexes from 2019 nCoV infected patients linked to viral loads and lung injury. Sci China Life Sci. doi:10.1007/s11427-020-1643-8

4. Wilson N, Kvalsvig A, Barnard LT, Baker MG (2020) Case-fatality risk estimates for COVID-19 calculated by using a lag time for fatality. Emerg Infect Ids. doi:10.3201/ eid2606.200320

5. ["RKI - Coronavirus SARS-CoV-2 - SARS-CoV-2 Steckbrief zur CoronavirusKrankheit-2019 (COVID-19)," n.d.)] https://rki.de/DE/Content/InfAZ/N/Neuartiges_ Coronavirus/Steckbrief.html. Accessed 10 October 2020

6. Masiero S, Zampieri D, Del Felice A (2020) The Place of Early Rehabilitation in Intensive Care Unit for COVID-19. Am J Phys Med Rehabil. doi:10.1097/ PHM.0000000000001478

7. Brugliera L, Spina A, Castellazzi P, Cimino P, Tettamanti A, Houdayer E, Arcuri P, Alemanno F, Mortini P, Iannaccone S. (2020) Rehabilitation of COVID-19 patients. J Rehabil Med. doi:10.2340/16501977-2678

8. Grund S, Gordon AL, van Balen R, Bachmann S, Cherubini A, Landi F, Stuck AE, Becker C, Achterberg WP, Bauer JM, Schols JMGA (2020) European consensus on core principles and future priorities for geriatric rehabilitation: consensus statement. Eur Geriatr Med. doi:10.1007/s41999-019-00274-1

9. Bachmann S, Finger C, Huss A, et al. (2010) Inpatient rehabilitation specifically designed for geriatric patients: Systematic review and meta-analysis of randomised controlled trials. BMJ. doi:10.1136/bmj.c1718
10. Caljouw MAA, Kruijdenberg SJM, de Craen AJM, Cools HJM, den Elzen WPJ, Gussekloo J (2013) Clinically diagnosed infections predict disability in activities of daily living among the oldest old in the general population: the Leiden 85-plus Study. Age and Ageing. doi:10.1093/ageing/aft033

11. Cameron ID, Kurrle SE (2002) Rehabilitation and older people. Med J Aust doi:10.5694/j.1326-5377.2002.tb04847.x

12. Connolly B (2015) Describing and measuring recovery and rehabilitation after critical illness. Curr Opin Crit Care. doi:10.1097/MCC.0000000000000233

13. Mehlhorn J, Freytag A, Schmidt K, Brunkhorst FM, Graf J, Troitzsch U, Schlattmann P, Wensing M, Gensichen J (2014) Rehabilitation interventions for postintensive care syndrome: a systematic review. Crit Care Med. doi:10.1097/CCM.0000000000000148

14. Major ME, Kwakman R, Kho ME, Connolly B, McWilliams D, Denehy L, Hanekom S, Patman S, Gosselink R, Jones C, Nollet F, Needham DM, Engelbert RH, van der Schaaf M (2016) Surviving critical illness: what is next? An expert consensus statement on physical rehabilitation after hospital discharge. Crit Care. doi:10.1186/ s13054-016-1508-x

15. van Dam van Isselt EF, van Eijk M, van Geloven N, Groenewegen-Sipkema KH, van den Berg JK, Nieuwenhuys CMA, Chavannes NH, Achterberg WP (2019) A Prospective Cohort Study on the Effects of Geriatric Rehabilitation Following Acute Exacerbations of COPD. J Am Med Dir Assoc. doi: 10.1016/j.jamda.2019.02.025

16. van Meijeren-Pont W, Volker G, Vliet Vlieland T, Goossens P (2019) Comparison of the responsiveness of the Utrecht Scale for Evaluation of Rehabilitation (USER) and the Barthel Index in stroke patients. Clin Rehabil. doi:10.1177/0269215519852130

17. Hsueh IP, Lin JH, Jeng JS, Hsieh CL (2002) Comparison of the psychometric characteristics of the functional independence measure, 5 item Barthel index, and 10 item Barthel index in patients with stroke. J Neurol Neurosurg Psychiatry. doi:10.1136/jnnp.73.2.188

18. Turner-Stokes L, Williams H, Rose H, Harris S, Jackson D (2010) Deriving a Barthel Index from the Northwick Park Dependency Scale and the Functional Independence Measure: are they equivalent? Clin Rehabil. doi:10.1177/0269215510375904

19. Donabedian, A (1988) The Quality of Care. JAMA. doi:10.1001/ jama.1988.03410120089033

20. Castor (2020). Certified online database. https://castoredc.com/security-statement/; https://www.castoredc.com Accessed 10 October 2020

21. Hopman-Rock M, van Hirtum H, de Vreede P, Freiberger E (2019) Activities of daily living in older community-dwelling persons: a systematic review of psychometric properties of instruments. Aging Clin Exp Res. doi:10.1007/s40520-018-1034-6

22. Bouwstra H, Smit EB, Wattel EM, van der Wouden JC, Hertogh CMPM, Terluin B, et al. (2019) Measurement properties of the barthel index in geriatric rehabilitation. J Am Med Dir Assoc. doi: 10.1016/j.jamda.2018.09.033

23. Collin C, Wade DT, Davies S, Horne V (1988) The Barthel ADL Index: A reliability study, International Disability Studies. doi:10.3109/09638288809164103

24. Sainsbury A, Seebass G, Bansal A, Young JB (2005) Reliability of the Barthel Index when used with older people, Age and Ageing. doi:10.1093/ageing/afi063

25. Kabboord, A.D., Godfrey, D., Gordon, A.L. et al. (2020) The modified functional comorbidity index performed better than the Charlson index and original functional comorbidity index in predicting functional outcome in geriatric rehabilitation: a prospective observational study. BMC Geriatr. doi:10.1186/s12877-020-1498-Z

26. Negrini S, Ferriero G, Kiekens C, Boldrini P. (2020) Facing in real time the challenges of the Covid-19 epidemic for rehabilitation. Eur J Phys Rehabil Med. doi: 10.23736/ S1973-9087.20.06286-3

27. Wang TJ, Chau B, Lui M, Lam GT, Lin N, Humbert S (2020) Physical Medicine and Rehabilitation and Pulmonary Rehabilitation for COVID-19. Am J Phys Med Rehabil. doi:10.1097/PHM.0000000000001505

28. Iannaccone S, Castellazzi P, Tettamanti A, et al. (2020) Role of Rehabilitation Department for Adult Individuals With COVID-19: The Experience of the San Raffaele Hospital of Milan. Arch Phys Med Rehabil. doi:10.1016/j.apmr.2020.05.01

29. Barker-Davies RM, O'Sullivan O, Senaratne KPP, et al. (2020) The Stanford Hall consensus statement for post-COVID-19 rehabilitation. Br J Sports Med. doi:10.1136/ bjsports-2020-102596

30. Vigorito C, Faggiano P, Mureddu GF (2020) COVID-19 pandemic: what consequences for cardiac rehabilitation?. Monaldi Arch Chest Dis. doi:10.4081/ monaldi.2020.1315

31. Lopez M, Bell K, Annaswamy T, Juengst S, Ifejika N (2020) COVID-19 Guide for the Rehabilitation Clinician: A Review of Nonpulmonary Manifestations and Complications. Am J Phys Med Rehabil. doi:10.1097/PHM.0000000000001479

32. Liu K, Zhang W, Yang Y, Zhang J, Li Y, Chen Y (2020) Respiratory rehabilitation in elderly patients with COVID-19: A randomized controlled study. Complement Ther Clin Pract. doi:10.1016/j.ctcp.2020.101166

33. Grund S., van Wijngaarden J.P., Gordon A.L. et al. (2020) EuGMS survey on structures of geriatric rehabilitation across Europe. Eur Geriatr Med. Europe. Eur Geriatr Med. doi.org/10.1007/s41999-019-00273-2 